\title{
The Economics and Ethics of Farm Animal Welfare - The Case of Chick Culling and its Alternatives
}

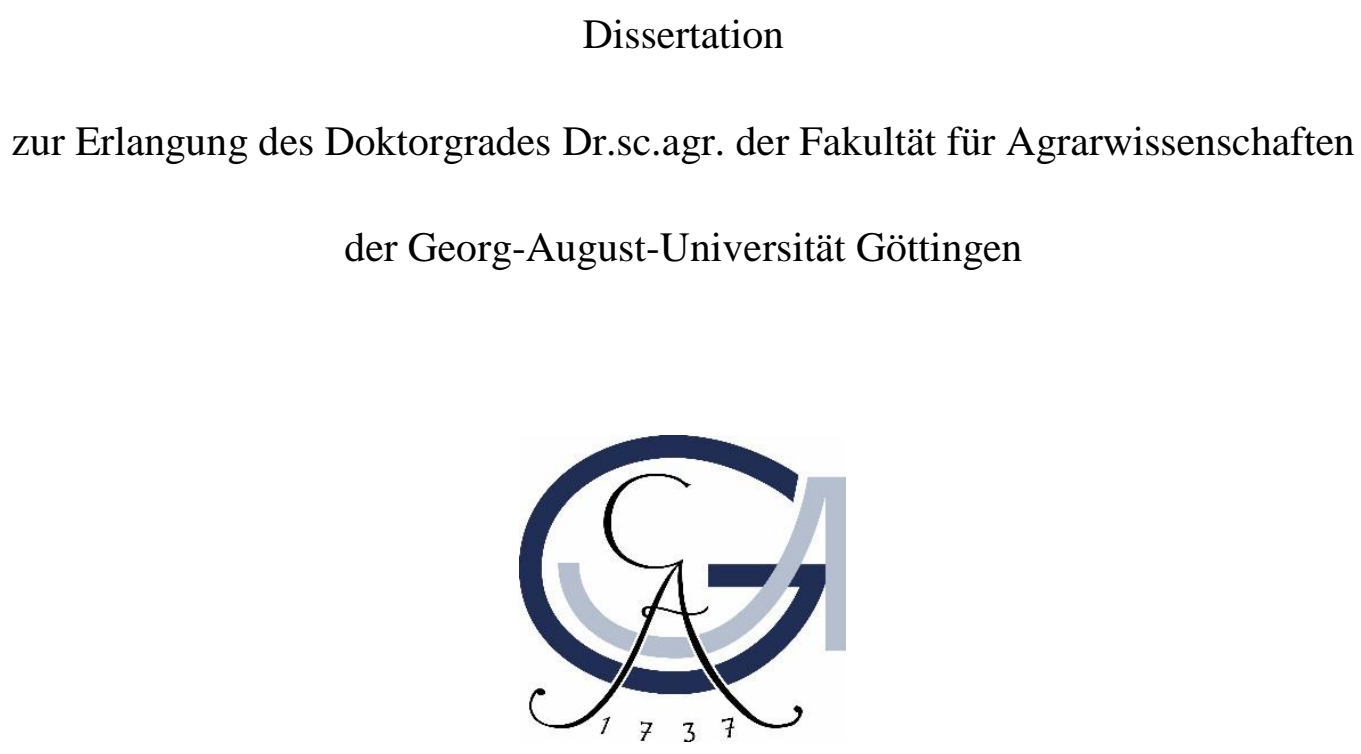

Vorgelegt von

Corrina Reithmayer

Geboren am 25. Mai 1989 in München

Göttingen, Februar 2020 


\section{D7}

1. Gutachter: $\quad$ Prof. Dr. Oliver Mußhoff

2. Gutachter: $\quad$ Prof. Dr. Achim Spiller

3. Gutachter: $\quad$ Prof. Dr. Guido Recke

Tag der mündlichen Prüfung: 27.01.2020 
Table of contents

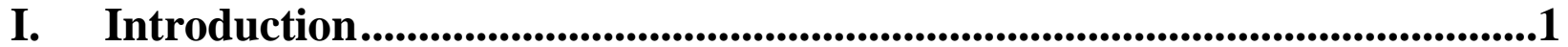

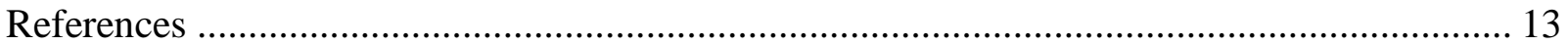

II. Alternatives to culling male chicks - the consumer perspective ................19

III. Consumer preferences for alternatives to chick culling in Germany ........20

IV. Societal attitudes towards in ovo gender determination as an alternative to chick culling ............................................................................................................................21

V. Look at that! - The effect pictures have on consumer preferences for in ovo gender determination as an alternative to culling male chicks ...........22

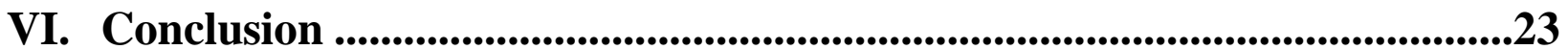

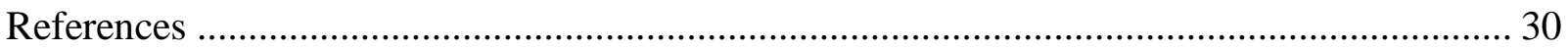

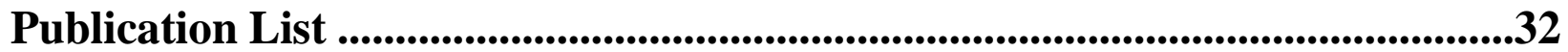

Erklärung über den geleisteten Eigenanteil der Arbeit .........................................33

Eidesstattliche Erklärungen..................................................................................34 


\section{Introduction}

Societal attitudes towards animals have evolved over time. Public opinions have influenced the moral status societies assign to animals, the legal protection they grant them and the way they utilize them. Ethical and economic goals form the ongoing field of tension that a society faces in the intercourse with its animals. This applied in the past and is still valid today.

This circumstance can be understood by taking into consideration the changing concept of animal sentience. Sentience can be described as the ability of a being "to evaluate the actions of others in relation to itself and third parties, to remember some of its own actions and their consequences, to assess risk, to have some feelings and to have some degree of awareness" (Broom, 2007). While easy to describe, proving the sentience of animals is challenging (Proctor, 2012). That could be why the concept of animal sentience has by far not always been universally recognized. Important philosophers, such as René Descartes and Thomas Aquinus, argued that animals were insentient and only equipped with "unconscious emotions" (Duncan, 2006; Rollin, 2006). However, controversial opinions about animal sentience have always been present throughout the centuries, with proponents among scientists also during the Renaissance (Duncan, 2006). Yet it was not before the epoch of the Enlightenment, when the concept of insentience was severely challenged, and found its most famous opponent in Jeremy Bentham. Bentham (1843) argued that animals could suffer as humans, which according to him should be the key characteristic in the evaluation of an animals' moral status.

The concept of animals being sentient became increasingly accepted among the scientific community from the beginning of the 20th century onwards (Duncan, 2006). However, how affective states in animals were to be evaluated - whether they were similar to human feelings and emotions or not - was another controversy among scientists. It was not until the 1970s and 1980s that it became widely accepted that animals had feelings. The capacity to feel forms the basis for well-being and therefore for the assessment of welfare (Duncan, 2006).

While the philosophical discussion about animal welfare centers around an animals' moral status and whether animals should be used at all by humans (what influential ethicists such as Regan (1985) and Singer (1975) have clearly negated in the past), the discipline of animal welfare science aims to assess and improve the welfare of animals under human management (Fraser, 1999). The diverse viewpoints clearly indicate that some distance exists between the 
two disciplines. For about three decades now, animal welfare scientists have been investigating farm animal welfare intensively; a growing body of literature offers a comprehensive empirical knowledge about the topic (Proctor et al., 2013).

The changing philosophical and scientific beliefs about animal sentience and animal welfare are reflected in the European animal protection legislation. In Europe, animal protection legislation which protects the animal itself from cruelty or suffering mainly began from the 1970s onwards (Rollin, 2006). This development was fortified in the 1980s, when animal welfare together with the upcoming discussions about environmental aims moved more into the focus (Deuffic \& Candau, 2006). Animal sentience was recognized in European legislation under the Amsterdam Treaty in 1997 (European Union, 1997).

Besides the scientific and philosophic discussion about animal sentience, feelings and welfare throughout the past centuries, the current societal debate about farm animal welfare in Europe had further drivers. In the 1950s, livestock production was intensified and industrialized (McEachern et al., 2007). From that time on, husbandry systems were widely associated with large numbers of animals and confinement, which were new to the society (Hart \& Mayda, 1998). Also breeding goals were reconsidered under the target of efficiency. This led to the use of animals which are highly specialized for their production purpose. The downside of efficiency was adverse effects on animal welfare. Intensive livestock production was first criticized in the 1960s in the book Animal Machines by Ruth Harrison (1964) (McEachern et al., 2007). The author argued that animals were sentient and felt stressed in industrial agriculture. Therefore, they suffered from the new production methods. This work led the public focus to intensive livestock production for the first time.

The debate about the consequences of intensive animal husbandry systems has been amplifying in recent years, triggered through the work of non-governmental organizations (Wilkins et al., 2005) and the provision of information through media channels (Tonsor \& Olynk, 2011). Certain consumer groups show a rising interest in ethical product attributes, as animal welfare friendly husbandry (Hobbs et al., 2002). Production practices which were common since the beginning of industrialized livestock husbandry are moving into the focus of societal debate and are criticized due to moral concern, e.g. gestation crates for sows (Tonsor et al., 2009) or cage housing and beak trimming for layer hens (Heng et al., 2013).

Account must be taken of the fact that any move to more welfare friendly or more extensive livestock production systems has real economic consequences: production costs increase. It 
is therefore essential to consider two aspects when implementing animal welfare improvements in livestock production. Firstly, animal protection regulation can be conducted at the national level in Europe, but products are traded internationally due to agreements with the World Trade Organization (Hobbs et al., 2002). With national regulation and international trade, disadvantages for domestic producers arise (Grethe, 2007; Hobbs et al., 2002). As a result, livestock production would be adversely affected, production might move to countries with lower animal welfare standards, which would contradict the original intent of the regulation (Grethe, 2007). Secondly, increased production standards and higher product prices might not meet the preferences of all consumers. Certain consumer segments are very price sensitive; they state a willingness to pay (WTP) for improvements in livestock husbandry conditions, which are smaller than the associated increases in production cost, as was found in studies analyzing choices for pork chops (Nilsson et al., 2006), ground beef (Peschel et al., 2016), pork neck (Grunert et al., 2018), and cage-free eggs (Lusk, 2018).

Particularly intensive poultry production has often been subject to criticism in recent years due to its negative impact on animal welfare. Two critiqued production norms should be highlighted in this respect, as they are exemplary for the influence of societal criticism on production standards. The first is cage housing of layer hens. This husbandry was introduced with the onset of industrial poultry production; cage housing was the widest spread husbandry system for layer hens from the 1950s onwards in the United States, European countries followed this development (Coles, 1954). However, this husbandry system was repeatedly criticized by animal rights organizations in a media-effective manner (Busch \& Spiller, 2018). The subject fell on fertile ground in a public that is increasingly interested in the welfare of animals and the conditions in which they are kept. Research about animal behavior made furthermore evident that barren cages do not let hens live their natural behaviors (Bhanja \& Bhadauria, 2018). Public debate and scientific evidence led to the ban of barren cages as housing for layer hens in 2012 in the EU (European Commission, 1999). Furthermore, US retailers announced to phase out eggs from cage husbandry by 2026 (Lusk, 2018).

The second production standard, which is currently highly discussed and most relevant in the context of this dissertation, is the culling of millions of day-old male layer-type chicks. The debate about this practice, consumer expectations towards potential alternatives and their WTP for them form the core theme of this dissertation. The issue is outlined in the 
following. The culling of day-old male layer chicks is a consequence of the intensification of poultry production. Laying performance and fattening efficiency are negatively correlated breeding aims (Krautwald-Junghanns et al., 2018). Over many years, the breeding goals "high laying performance" or "good fattening performance" were pursued. Hence, intensive poultry production is very efficient, with chicken highly adapted to one of the two production purposes. As a consequence, layer breeds have poor fattening performance. Meat production with layer strains is associated with around $70 \%$ higher production costs (Damme \& Ristic, 2003). Thus, fattening of male layer chicks was no longer economically viable when competing with specialized meat breeds. Male chicks from layer hen production became unnecessary and thus they started to be culled after hatch. This practice is currently the industry standard in conventional and organic egg production in most Western countries. At present, the practice affects approximately 330 million animals annually in the EU (European Commission, 2008), of which around 45 million are produced in Germany.

In Germany, a societal debate was initiated about whether this economically motivated culling of male chicks is morally admissible. The point of issue is not only related to animal welfare, as long as killing happens in a way that pain is avoided. It is considered an ethical issue if it is acceptable to produce animals which serve no purpose in agriculture and are killed for this reason at the beginning of their lives (Bruijnis et al., 2015). The topic has been very present in public discussions also in other western societies, as the Netherlands (Leenstra et al., 2011). Furthermore, in Germany, there has been a legal dispute about the practice since 2013, which mainly took place in the federal state of North Rhine-Westphalia, but also in 2019 at the federal level. It was legally disputed whether the economic interests underlying the practice were a "meaningful reason" in the sense of the German animal protection law.

Against the background of societal and judicial debates, governmental representatives, researchers, and retailers initiated a search for alternatives to the practice (German Federal Ministry of Food and Agriculture, 2017). Two alternatives emerged which can be realized in practice and their implementation is currently being pursued. The first one is dual-use poultry production. In a dual-use system, hens from either layer breeds or less specialized dual-purpose breeds are used for egg production and males are reared for slaughter. The second alternative to circumvent the culling of layer-type cockerels is gender determination in the incubated egg ("in ovo"). In ovo gender determination allows for the identification of eggs with male embryos during incubation in the hatcheries (Weissmann et al., 2013). As a 
consequence, respective eggs can be removed from the incubator and the hatching of male chicks is prevented. Different technological solutions have been discussed, allowing for gender determination at different stages of embryonic development (Krautwald-Junghanns et al., 2018).

Both alternatives can be considered advantageous with respect to ethical concerns in comparison to the status quo. However, the alternatives are also not free from controversy as they raise new ethical dilemmas. Dual-use poultry production is associated with an increased use of feed and water and an increased manure output compared to the current production scheme (Damme \& Ristic, 2003). Its environmental burden is therefore higher. Also the destruction of a viable embryo as a consequence of in ovo gender determination was shown to be of moral concern in previous studies (Leenstra et al., 2011; Bruijnis et al., 2015).

Besides these ethical considerations, chick-culling-free production systems are followed by economic consequences. Implementations of alternative systems will increase production costs, which will be handed on to consumers through higher egg prices. A conventional dualuse barn system with dual-purpose chicken is associated with a production cost increase which amounts to $€ 0.02$ per egg, for layer hybrids this cost increase amounts to $€ 0.01$ per egg (Diekmann et al., 2017). In organic egg production, dual-use poultry comes with a price increase of $€ 0.04$ per egg (Bruderhahn Initiative Deutschland, 2019). The price increase for in ovo gender determination amounts between $€ 0.01$ and $€ 0.03$ per egg consumed (Seleggt, 2019).

The culling of day-old male layer chicks is therefore a highly topical subject which exemplifies very well the controversy between ethical and economic goals of livestock husbandry. Knowledge about consumer attitudes and WTP regarding chick culling alternatives is instructive for egg producers, egg marketers and regulators of production standards.

The scientific literature on consumer attitudes towards animal welfare in poultry production gives evidence for considerable WTP for improvements of chicken welfare. Mørkbak and Nordström (2009) investigated attitudes towards food safety and rearing methods and found a positive WTP for chickens reared outdoors. WTP was even higher after participants were given particular information about the rearing methods. Bennett and Blaney (2003) conducted an experimental survey among UK citizens and found vast support (79\% of 
respondents) for a ban of cage eggs in the EU. Carlsson et al. (2007) investigated respondents' attitudes towards a ban of battery cages for chickens. The authors found a positive WTP for free-range production in comparison to battery-cages.

Public surveys focusing specifically on consumer attitudes towards chick culling alternatives were conducted in Germany, Switzerland and the Netherlands (Brümmer et al., 2018; Gangnat et al., 2018; Gremmen et al., 2018; Leenstra et al., 2011). These studies showed that informed citizens are considerate of the dilemmas between different ethical considerations as well as economic goals associated with the alternatives to culling day-old chicks (Brümmer et al., 2018; Leenstra et al., 2011). The use of culled male chicks, the husbandry conditions of cockerels when reared for slaughter, environmental concerns and moral evaluation of in ovo gender determination could be identified as determinants of consumer attitudes. Furthermore, price increases of poultry products due to changes in egg production were discussed critically.

Although attitudes towards chick culling alternatives have been regarded in the scientific literature, a comprehensive and up-to-date analysis of consumers' preferences for the alternatives, which will soon make up the offer on the market, is missing. German consumers will soon be confronted with respective eggs in their every-day life (at least as long as they are egg-eaters). It is unknown what they are willing to pay for these products, and which expectations they have with regard to the design of the alternatives to chick culling. Further research is therefore necessary to comprehensively examine societal preferences for this complex topic. This dissertation aims to investigate preferences and WTP for the alternatives which are soon to be on the market, with a special focus on attitudes towards in ovo screening, as this technical solution might soon be the industry standard in Germany.

At the time of investigation, not all alternatives to chick culling were yet available on the German market. It was therefore necessary to employ a stated preference approach and to create a hypothetical market situation. A method which is widely applied in the elicitation of environmental valuation or food preferences are discrete choice experiments (DCE) (Grunert et al., 2018; Hoyos, 2010; Liljenstolpe, 2008). This experimental method enables to derive information about individual preferences and also WTP from observed choice behavior (Louviere et al., 2010). Choice behavior is monitored in a series of intentionally designed hypothetical choice situations. The great benefit of DCEs is that they allow for the individual evaluation of single product features (Louviere et al., 2010). In this way, 
conclusions can be drawn regarding the preferences for single characteristics of products or regarding attitudes towards political initiatives. DCEs are a relatively implicit form of preference elicitation.

To investigate consumer attitudes for the alternatives to chick culling in the framework of this dissertation, two DCEs were developed. The first DCE was designed to investigate respondents' preferences and WTP for the two alternatives to chick culling which will soon be available on the German market, dual-use poultry and in ovo gender determination. The second DCE focused on the investigation of respondents' expectations regarding different aspects of the in ovo technology as an alternate to chick culling, as well as their respective WTP. Each DCE was integrated into a questionnaire containing furthermore surveys on socioeconomic background as well as attitudinal questions. Primary data was collected from anonymous online surveys, which were distributed by a data panelist (respondi AG, Cologne, Germany) among German respondents according to predefined quotas. The first questionnaire was distributed to 400 participants in 2018; an additional 126 participants were recruited in early 2019. The second survey was distributed to a sample of 482 respondents between December 2018 and March 2019. All samples were achieved to be representative for the German population regarding respondents' distribution of age, highest educational attainment and geographical distributions among federal states.

This dissertation consists of four studies which used the data obtained from the described surveys. The first two studies analyzed data obtained from the first survey. They evaluate WTP for and heterogeneity towards dual-use poultry and in ovo screening among German consumers. For studies three and four, the second dataset was used in order to comprehensively analyze consumer attitudes towards aspects of in ovo gender determination as chick culling alternative. The four studies are presented in the following paragraphs.

The first study (chapter II) Alternatives to culling male chicks - the consumer perspective (accepted for publication in British Food Journal), focuses on the investigation of consumer preferences and WTP for the alternatives to the culling of male layer chicks which are already or soon to be available on the market. These are namely gender determination of incubated eggs (in ovo) and dual-use poultry with cockerels in barn or free-range husbandry. Furthermore, consumer approval for different certifying bodies who issue labels about production claims was analyzed in the context of eggs from dual-use poultry. 
The German government announced to phase out the practice of chick culling during the next years, when in ovo gender determination will be market mature (German Federal Ministry of Food and Agriculture, 2017). German consumers are therefore likely to be the first, to be confronted with eggs associated with in ovo screening as an industry standard, and eggs from dual-use poultry as an alternative. Consequently, egg prices will rise, as increases in production cost will be handed on to consumers. As eggs from dual-use poultry will probably be associated with higher price increases, they will be labelled in order to differentiate from conventional products and to obtain the price premium necessary to make this production scheme economic.

Consumer attitudes to chick culling alternatives have been subject to former studies through focus group discussions in Germany (Brümmer et al., 2018) and public surveys in the Netherlands (Leenstra et al., 2011; Gremmen et al., 2018) and Switzerland (Gangnat et al., 2018). The results reveal a multi-faceted image of consumer attitudes. The in ovo technology was approved as a good alternative to the current practice in surveys among Dutch and Swiss citizens (Leenstra et al., 2011; Gangnat et al., 2018) when conducted before incubation. On the contrary, the destruction of chicken embryos was greatly disapproved. A dual-use system with dual-purpose chickens was supported from a moral point of view among Dutch and German consumers (Leenstra et al., 2011; Brümmer et al., 2018). However, respective price increases and the departure from efficient egg production were discussed as disadvantages.

When eliciting consumer attitudes towards dual-use poultry, previous studies did not distinguish between husbandry types, although this factor can be considered decisive in the marketing of corresponding eggs. In former studies, free-range husbandry of chickens was associated with higher animal welfare and also a higher WTP by participants (Van Loo et al., 2011; Carlsson et al., 2005). Citizens' attitudes towards in ovo gender determination were investigated only marginally. Furthermore, former studies employed focus group discussions, open-ended questions, or Likert Scale attitudinal questions when investigating WTP for chick culling alternatives. These methods can lead to biased WTP estimates, whereas more complex methods can render more reliable results.

An important factor in the marketing of dual-use eggs is labeling. Products from dual-use poultry are credence goods; they are indistinguishable from conventional products. This makes labeling a crucial means in the marketing of corresponding products, and opens the question by whom labeling should be conducted. Consumer approval of different certifying 
bodies differs, according to trust in the respective institution (Janssen et al., 2016). No recent studies on consumer preferences for different certification bodies in Germany have been conducted. Consequently, a research gap exists regarding preference and WTP estimation for the alternatives to chick culling which will soon make up the offer on the market, and preferences for associated product certification. The first presented study therefore aims to answer the following research questions:

(1) What are consumer preferences for poultry production systems without chick culling?

(2) Is cockerels' husbandry type a crucial characteristic for the acceptance of dual-use poultry?

(3) Which certifying body is preferred for the labelling of eggs from dual-use systems?

To answer these research objectives, a representative sample of 526 German respondents obtained from the first online survey was investigated. The first DCE offered a familiar choice situation between boxes of eggs with varying attributes to respondents. Attributes referred to the handling of male chicks, the associated price increase as well as the product labeling. Through the analysis of the sequence of decision making situations provided in the first DCE, aggregate preferences and WTP for the discussed alternatives to chick culling can be obtained. Furthermore respondents' approval for labels from different certifying bodies can be determined.

The investigations conducted in the first study are continued and deepened in the second presented article (chapter III), titled Consumer preferences for alternatives to chick culling in Germany (published in Poultry Science). The paper explores the heterogeneity of preferences and WTP regarding the alternatives to chick culling: in ovo gender determination and dual-use poultry in barn or free-range husbandry.

Evidence from former studies showed that price sensitivity and attitudes towards animal welfare or environmentally friendly production are very heterogeneous among the population (Peschel et al., 2016; Grunert et al., 2018). Regarding the egg market, certain segments could be found which differed in the degree of price sensitivity and in preferences for hens' husbandry conditions (Gracia et al., 2014; Kontoleon \& Yabe, 2006). Besides preferences, socioeconomic characteristics and price sensitivity could be shown to be determinants of attitude (Lagerkvist \& Hess, 2011; van Loo et al., 2011). It can therefore be assumed that also the attitudes towards chick culling alternatives are heterogeneous among 
the population. So far, to the best of our knowledge, no scientific study exists that analyzes the distribution of consumer preferences towards the alternatives to chick culling. The aim of the second study therefore is to answer the following research questions:

(1) Can disjunct consumer segments with differing preferences and WTP for chick culling alternatives be identified?

(2) Do members of these segments differ in their characteristics?

For this objective, data from the first online survey from a representative sample of 400 German citizens is investigated. Preferences can be derived from observed choice behavior between boxes of eggs, which are described by different combinations of attributes. A segmentation approach renders comprehensive insights about the heterogeneity of respondents' attitudes.

The third study (chapter IV) titled Societal attitudes towards in ovo gender determination as an alternative to chick culling (published as DARE Discussion Paper 1906) focuses on German citizens' preferences for different aspects of in ovo gender determination technologies. In particular, the heterogeneity in attitudes towards relevant factors of livestock production, and towards preferences and WTP for important attributes associated with in ovo screening is analyzed.

In ovo gender determination is supposed to substitute chick culling as an industry standard in Germany in the near future and might also substitute the current practice in other countries where chick culling is exposed to public debate. Different in ovo technologies are discussed which enable gender identification at different days of incubation (Krautwald-Junghanns et al., 2018). They are therefore associated with different stages of embryonic development, which might be crucial for the acceptance of the new technology. The destruction of a viable embryo associated with in ovo screening of incubated eggs was found to be viewed critically by certain individuals (Leenstra et al., 2011). Gremmen et al. (2018) found heterogeneous attitudes for different in ovo technologies among Dutch respondents - both approval and disapproval was present. Two other crucial factors can be assumed to be relevant for the acceptance of in ovo screening. First, a meaningful use of by-products (screened out eggs as well as male chicks) was mentioned as a determinant of consent for the respective alternative (Leenstra et al., 2011). Different usages are discussed for screened out eggs, as e.g. the use as fodder or the use in the chemical industry. Second, an error rate applies for all gender determination technologies, leading to the screening out of eggs with female embryos and 
generally to a higher use of animals. High inaccuracy in gender determination might therefore be a motive to reject in ovo screening. Although in ovo screening is to be applied country-wide in Germany in the near future, no study exists so far which analyzes attitudes towards the different aspects of in ovo gender determination. The third study therefore aims to answer the following two research questions:

(1) Can segregated groups of consumers, which differ in attitudes towards the characteristics of in ovo gender determination, be identified?

(2) Is the membership in groups associated with other characteristics; namely preferences for enhanced animal welfare, attitudes towards technological advance in agriculture and confidence in animal protection legislation?

For this objective, data from 482 German respondents from the second online survey was analyzed. The analysis of attitudinal questions allows identifying relevant factors underlying personal attitude. The investigation of the sequence of intentionally designed decision making situations from the second DCE allows for a sophisticated analysis of heterogeneity in preferences and WTP for single characteristics of the in ovo technology.

The fourth study (chapter V) Look at that! - The effect pictures have on consumer preferences for in ovo gender determination as an alternative to culling male chicks (published as DARE Discussion Paper 1907) investigates how the provision of pictures influences consumer choice behavior in the context of chick culling and different in ovo gender determination technologies.

The public discussion on farm animal welfare and husbandry conditions has widely been driven by pictures in recent years. This is especially true as mass media has become an important source of information about agriculture for many people (Mayfield et al., 2007; Wunderlich \& Gatto, 2015), and pictures are readily available everywhere and at any time through social media channels. Furthermore, pictures are remembered better (Childers \& Houston, 1984) and trigger stronger emotions compared to text (Hajcak \& Olvet, 2008). In this way they can drive societal debates, which in turn can lead to real consequences for production standards. The debate about cage housing for layer hens is an example - it was moved to the public focus by non-governmental organizations who provided pictures and videos of confined hens in cages (Busch \& Spiller, 2018). The debate finally led to the ban of the husbandry system in 2012 (European Commission, 1999). Based on these considerations, there is reason to assume that images can affect societal approval in the 
context of chick culling and in ovo screening. However, this has not been investigated yet. The presented paper therefore aims to answer the following research question:

(1) Does the provision of pictures of chicks or incubated eggs at different stages of embryonic development influence respondents' choice behavior for respective alternatives?

For this research objective, data obtained from the second online survey from a representative sample of 482 German respondents is analyzed. An experimental procedure with two DCEs was designed. The combinations of attributes in the choice situations were identical in both DCEs. Yet the first DCE described the attribute referring to the day of gender determination through plain text only. The second described this attribute additionally through pictures of incubated eggs or a chick. This design allows analyzing differences in choice behavior that can be attributed to the influence of the pictures. The potential of pictures to cause societal concern and affect egg demand in the context of chick culling and in ovo screening can as a result be evaluated.

The four introduced articles are presented in the subsequent chapters. The dissertation provides a sophisticated analysis of societal attitudes towards the economical and ethical problems associated with the practice of chick culling and its alternatives. Specifically, a profound investigation of attitudes regarding in ovo gender determination is conducted. The dissertation concludes with a summary of the findings and their implications for practitioners and stakeholders in poultry production, as well as political decision makers. As the debate about culling day-old chicks is the prime example of an ethically complex and emotionally debated animal welfare problem, an outlook on possible drivers which might be relevant for the future development of livestock production concludes this dissertation. 


\section{References}

Bennett, R. M., \& Blaney, R. J. P. (2003). Estimating the benefits of farm animal welfare legislation using the contingent valuation method. Agricultural Economics, 29(1), 85-98.

Bentham, J., \& Browning, J. (1843). The works of Jeremy Bentham. London: Simpkin, Marshall, \& Co.

Bhanja, S. K., \& Bhadauria, P. (2018). Behaviour and welfare concepts in laying hens and their association with housing systems. Indian Journal of Poultry Science, 53(1), 1-10.

Broom, D. M. (2007). Cognitive ability and sentience: Which aquatic animals should be protected?. Diseases of Aquatic Organisms, 75(2), 99-108.

Bruderhahn Initiative Deutschland. (2019). 4 Cent für die Ethik [4 cents for ethics]. https://www.bruderhahn.de/was_wir_aendern.html\#4cent. Accessed 7 December 2019.

Bruijnis, M. R. N., Blok, V., Stassen, E. N., \& Gremmen, H. G. J. (2015). Moral "Lock-In" in Responsible Innovation: The Ethical and Social Aspects of Killing Day-Old Chicks and Its Alternatives. Journal of Agricultural and Environmental Ethics, 28(5), 939-960.

Brümmer, N., Christoph-Schulz, I. and Rovers, A. K. (2018). Consumers' perspective on dual-purpose chickens as alternative to the killing of day-old chicks. International Journal on Food System Dynamics, 9(5), 390-398.

Busch, G., \& Spiller, A. (2018). Pictures in public communications about livestock farming. Animal Frontiers, 8(1), 27-33.

Carlsson, F., Frykblom, P., \& Lagerkvist, C. J. (2005). Consumer Preferences for Food Product Quality Attributes from Swedish Agriculture. AMBIO: A Journal of the Human Environment, 34(4), 366-370.

Carlsson, F., Frykblom, P., \& Lagerkvist, C. J. (2007). Farm Animal Welfare-Testing for Market Failure. Journal of Agricultural and Applied Economics, 39(1), 61-73.

Childers, T. L., \& Houston, M. J. (1984). Conditions for a picture-superiority effect on consumer memory. Journal of Consumer Research, 11(2), 643-654.

Coles, R. (1954). Changes in the pattern of poultry keeping. Journal of the Royal Agricultural Society of England, (115), 69-82. 
Damme, K., \& Ristic, M. (2003). Fattening performance, meat yield and economic aspects of meat and layer type hybrids. World's Poultry Science Journal, 59(1), 50-53.

Deuffic, P., \& Candau, J. (2006). Farming and Landscape Management: How French Farmers are Coping with the Ecologization of Their Activities. Journal of Agricultural and Environmental Ethics, 19(6), 563-585.

Diekmann, J., Hermann, D., \& Mußhoff, O. (2017). Wie hoch ist der Preis auf Kükentötungen $\mathrm{zu}$ verzichten? Bewertung des Zweinutzungshuhn- und Bruderhahnkonzepts als wirtschaftliche Alternative zu Mast- und Legehybriden [What is the price of not culling chicks? Evaluation of the dual-purpose chicken concept and brother cockerel concept as economic alternatives to broiler and layer hybrids]. Berichte über Landwirtschaft - Zeitschrift für Agrarpolitik und Landwirtschaft, 95(1).

Duncan, I. J. (2006). The changing concept of animal sentience. Applied Animal Behaviour Science, 100(1-2), 11-19.

European Commission. (1999). COUNCIL DIRECTIVE 1999/74/EC of 19 July 1999 laying down minimum standards for the protection of laying hens. Official Journal of the European Communities, L203/53.

European Commission. (2008). Questions and Answers on the proposal for the protection of animals at the time of killing (MEMO/08/574). Accessed 5 August 2019. https://ec.europa.eu/food/animals/welfare/practice/slaughter_en

European Union. (1997). Treaty of Amsterdam amending the Treaty on European Union, the Treaties establishing the European Communities and certain related acts. Accessed 5 December 2019. http://publications.europa.eu/de/publication-detail//publication/c30a3a4e-1707-4c93-a95e-36f9a8a7f3eb

Fraser, D. (1999). Animal ethics and animal welfare science: Bridging the two cultures. Applied Animal Behaviour Science, 65(3), 171-189.

Gangnat, I. D. M., Mueller, S., Kreuzer, M., Messikommer, R. E., Siegrist, M., \& Visschers, V. H. M. (2018). Swiss consumers' willingness to pay and attitudes regarding dualpurpose poultry and eggs. Poultry Science, 97(3), 1089-1098. 
German Federal Ministry of Food and Agriculture. (2017). Alternativen zum Töten männlicher Küken [Alternatives to the culling of male chicks]. Accessed 3 May 2019. https://www.bmel.de/DE/Tier/Tierwohl/_texte/Tierwohl-Forschung-In-Ovo.html

Gracia, A., Barreiro-Hurlé, J., \& Galán, B. L. (2014). Are Local and Organic Claims Complements or Substitutes? A Consumer Preferences Study for Eggs. Journal of Agricultural Economics, 65(1), 49-67.

Gremmen, B., Bruijnis, M. R. N., Blok, V., \& Stassen, E. N. (2018). A Public Survey on Handling Male Chicks in the Dutch Egg Sector. Journal of Agricultural and Environmental Ethics, 31(1), 93-107.

Grethe, H. (2007). High animal welfare standards in the EU and international trade - How to prevent potential 'low animal welfare havens'?. Food Policy, 32(3), 315-333.

Grunert, K. G., Sonntag, W. I., Glanz-Chanos, V., \& Forum, S. (2018). Consumer interest in environmental impact, safety, health and animal welfare aspects of modern pig production: Results of a cross-national choice experiment. Meat science, 137, 123-129.

Hajcak, G., \& Olvet, D. M. (2008). The persistence of attention to emotion: Brain potentials during and after picture presentation. Emotion (Washington, D.C.), 8(2), 250-255.

Harrison, R. (1964). Animal Machines. London: Vincent Stuart Ltd.

Hart, J. F., \& Mayda, C. (1998). The Industrialization of Livestock Production in The United States. Southeastern Geographer, 38(1), 58-78.

Heng, Y., Peterson, H., \& Li, X. (2013). Consumer Attitudes toward Farm-Animal Welfare: The Case of Laying Hens. Journal of Agricultural and Resource Economics, 38(3), 418434.

Hobbs, A. L., Hobbs, J. E., Isaac, G. E., \& Kerr, W. A. (2002). Ethics, domestic food policy and trade law: Assessing the EU animal welfare proposal to the WTO. Food Policy, 27(5$6), 437-454$.

Hoyos, D. (2010). The state of the art of environmental valuation with discrete choice experiments. Ecological Economics, 69(8), 1595-1603. 
Janssen, M., Rödiger, M., \& Hamm, U. (2016). Labels for Animal Husbandry Systems Meet Consumer Preferences: Results from a Meta-analysis of Consumer Studies. Journal of Agricultural and Environmental Ethics, 29(6), 1071-1100.

Kontoleon, A., \& Yabe, M. (2006). Market Segmentation Analysis of Preferences for GM Derived Animal Foods in the UK. Journal of Agricultural \& Food Industrial Organization, 4(1).

Krautwald-Junghanns, M.-E., Cramer, K., Fischer, B., Förster, A., Galli, R., Kremer, F., Mapesa, E. U., Meissner, S., Preisinger, R., Preusse, G., Schnabel, C., Steiner, G., \& Bartels, T. (2018). Current approaches to avoid the culling of day-old male chicks in the layer industry, with special reference to spectroscopic methods. Poultry Science, 97(3), $749-757$.

Lagerkvist, C. J., \& Hess, S. (2011). A meta-analysis of consumer willingness to pay for farm animal welfare. European Review of Agricultural Economics, 38(1), 55-78.

Leenstra, F., Munnichs, G., Beekman, V., van den Heuvel-Vromans, E., Aramyan, L., \& Woelders, H. (2011). Killing day-old chicks? Public opinion regarding potential alternatives. Animal Welfare, 20(1), 37-45.

Liljenstolpe, C. (2008). Evaluating animal welfare with choice experiments: An application to Swedish pig production. Agribusiness, 24(1), 67-84.

Louviere, J. J., Hensher, D. A., Swait, J., \& Adamowicz, W. L. (2010). Stated choice methods: Analysis and applications (7. printing). Cambridge: Cambridge Univ. Press.

Lusk, J. L. (2018). Consumer preferences for cage-free eggs and impacts of retailer pledges. Agribusiness, 35(2), 129-148.

Mayfield, L. E., Bennett, R. M., Tranter, R. B., \& Wooldridge, M. J. (2007). Consumption of welfare-friendly food products in Great Britain, Italy and Sweden, and how it may be influenced by consumer attitudes to, and behaviour towards, animal welfare attributes. International Journal of Sociology of Food and Agriculture, 15(3), 59-73.

McEachern, M. G., Schröder, M. J., Willock, J., Whitelock, J., \& Mason, R. (2007). Exploring ethical brand extensions and consumer buying behaviour: The RSPCA and the "Freedom Food" brand. Journal of Product \& Brand Management, 16(3), 168-177. 
Mørkbak, M. R., \& Nordström, J. (2009). The Impact of Information on Consumer Preferences for Different Animal Food Production Methods. Journal of Consumer Policy, $32(4), 313-331$.

Nilsson, T., Foster, K., \& Lusk, J. L. (2006). Marketing Opportunities for Certified Pork Chops. Canadian Journal of Agricultural Economics/Revue canadienne d'agroeconomie, 54(4), 567-583.

Peschel, A. O., Grebitus, C., Steiner, B., \& Veeman, M. (2016). How does consumer knowledge affect environmentally sustainable choices? Evidence from a cross-country latent class analysis of food labels. Appetite, 106, 78-91.

Proctor, H. (2012). Animal Sentience: Where Are We and Where Are We Heading? Animals: An Open Access Journal from MDPI, 2(4), 628-639.

Proctor, H. S., Carder, G., \& Cornish, A. R. (2013). Searching for Animal Sentience: A Systematic Review of the Scientific Literature. Animals: An Open Access Journal from MDPI, 3(3), 882-906.

Regan, T. (1985). The Case for Animal Rights (1. paperback print). Berkeley: Univ. of California Press.

Rollin, B. E. (2006). The regulation of animal research and the emergence of animal ethics: A conceptual history. Theoretical Medicine and Bioethics, 27(4), 285-304.

Seleggt. Fragen und Antworten zum SELEGGT Verfahren. Accessed 5 December 2019. http://www.seleggt.de/wp-content/uploads/2018/04/SELEGGT

Singer, P. (1975). Animal Liberation: A new Ethics for our Treatment of Animals. New York: Random House.

Tonsor, G. T., \& Olynk, N. J. (2011). Impacts of Animal Well-Being and Welfare Media on Meat Demand. Journal of Agricultural Economics, 62(1), 59-72.

Tonsor, G. T., Olynk, N., \& Wolf, C. (2009). Consumer Preferences for Animal Welfare Attributes: The Case of Gestation Crates. Journal of Agricultural and Applied Economics, 41(3), 713-730. 
Van Loo, E. J., Caputo, V., Nayga, R. M., Meullenet, J.-F., \& Ricke, S. C. (2011). Consumers' willingness to pay for organic chicken breast: Evidence from choice experiment. Food Quality and Preference, 22(7), 603-613.

Weissmann, A., Reitemeier, S., Hahn, A., Gottschalk, J., \& Einspanier, A. (2013). Sexing domestic chicken before hatch: a new method for in ovo gender identification. Theriogenology, 80(3), 199-205.

Wilkins, D. B., Houseman, C., Allan, R., Appleby, M. C., Peeling, D., \& Stevenson, P. (2005). Animal welfare: The role of non-governmental organisations. Revue scientifique et technique (International Office of Epizootics), 24(2), 625-638.

Wunderlich, S., \& Gatto, K. A. (2015). Consumer perception of genetically modified organisms and sources of information. Advances in Nutrition (Bethesda, Md.), 6(6), 842851. 


\title{
II. Alternatives to culling male chicks - the consumer perspective
}

Authors: Corrina Reithmayer, Oliver Mußhoff, Michael Danne

Status: Published online in British Food Journal (in print).

https://doi.org/10.1108/BFJ-05-2019-0356

\begin{abstract}
Purpose - Investigating consumer preferences for boxes of eggs which are produced without the culling of male layer-type chicks in layer hen production. Furthermore, investigating consumer preferences for labels from different certifying bodies.

Design - An online survey including a discrete choice experiment was conducted among 526 German consumers in 2018 and early 2019. Mixed logit models in preference and willingness to pay (WTP) space were estimated.

Findings - The preferred alternative is gender determination of incubated eggs, but also dual-use poultry with free-range rearing of cockerels was approved. Labels from public authorities and the animal protection organisation were highly approved. By contrast, retailers were not considered suitable for the certification of production claims.
\end{abstract}

Research limitations - A hypothetical setting was employed. A revealed preferences approach is suggested for future research.

Practical implications - Evidence for a wide approval of in ovo gender determination was found. Free-range rearing of cockerels was the most promising for the marketing of dual-use poultry products. Furthermore, public authorities and well-established third parties should engage in the field of animal welfare labeling.

Originality/value - This is the first study focusing on preferences and WTP for alternatives to chick culling which will soon be available on the market, and for institutions certifying production claims. Findings help political decision makers, when looking for alternatives to the culling of day-old chicks, which are considered more acceptable by the public.

Keywords: chick culling; choice experiment; dual-use poultry; egg; in ovo; label 


\title{
III. Consumer preferences for alternatives to chick culling in Germany
}

\author{
Authors: Corrina Reithmayer, Oliver Mußhoff \\ Status: Published in Poultry Science, 98(10), 4539-4548. \\ https://doi.org/10.3382/ps/pez272
}

\begin{abstract}
The use of highly specialized breeds in poultry production has led to the situation in which fattening layer-type males is not economically viable, when competing with conventional broiler meat. The vast majority of male layer chicks are therefore culled soon after hatching. Ethical concern about this practice has led to a public debate in a number of countries, its tenor seems unambiguous: the practice should end. Political and industrial representatives have also promoted putting an end to chick culling. The two alternatives which are already available or soon to be on the market in a number of countries are dual-use poultry production and in ovo gender determination. However, the alternatives are also not free from controversy. The presented study analyzes consumer attitudes towards these two alternatives. A discrete choice experiment on eggs with different production attributes was conducted among a sample of 400 German citizens. Results from a latent class model show that there is considerable heterogeneity in preferences, which can be depicted in five consumer segments. Consumer segments differ significantly in socioeconomic characteristics and attitudes towards chick culling alternatives. One segment decides mainly based on product price. However, $28 \%$ of the sample show no price sensitivity, but choose based on other product attributes such as the preferred chick culling alternative or egg type. We find wide approval for in ovo gender determination with no segment disapproving of the technology. When it comes to dual-use poultry, the type of husbandry of cockerels is crucial for the approval of this production scheme. Rearing male chicks in free-range husbandry is the preferred alternative for one segment representing $27 \%$ of the sample. Results provide empirical evidence for a diversified egg demand, indicating diverse expectations for poultry production in the future.
\end{abstract}

Keywords: chick; in ovo; dual-use poultry; latent class; consumer 
IV Societal attitudes towards in ovo gender determination as an alternative to chick culling

\title{
IV. Societal attitudes towards in ovo gender determination as an alternative to chick culling
}

Authors: Corrina Reithmayer, Michael Danne, Oliver Mußhoff

Status: Published as DARE Discussion Paper No. 1906 (2019).

http://hdl.handle.net/10419/206718

\begin{abstract}
In ovo gender determination of incubated eggs can be a large-scale substitute to the culling of male chicks in layer hen production. However, the technology raises new ethical concerns which relate to the sensitivity of the embryo, as well as how the screened out eggs will be used afterwards and the accuracy of gender determination. In order to comprehensively investigate consumer attitudes towards this new technology, a questionnaire including a choice experiment was distributed to a representative sample of 482 German consumers between December 2018 and March 2019. The data was analyzed by an explorative factor analysis and a latent class analysis. Results indicate that the sample can be divided into four segments, which differ in preferences for production attributes, attitudes and price sensitivity. Attitudinal differences are found regarding respondents' approval of the technical advances in agricultural production, confidence in legal regulations and the endorsement of enhanced livestock production conditions. Both a meaningful usage of byproducts and a high rate of accuracy are crucial factors for the acceptance of in ovo gender determination for the majority of respondents. However, response behavior of one segment, representing $11 \%$ of the sample, indicates the disapproval of both chick culling and in ovo screening.
\end{abstract}

Keywords: chick; choice experiment; culling; gender determination; in ovo; latent class 
V Look at that! - The effect pictures have on consumer preferences for in ovo gender determination as an alternative to culling male chicks

\title{
V. Look at that! - The effect pictures have on consumer preferences for in ovo gender determination as an alternative to culling male chicks
}

\author{
Authors: Corrina Reithmayer, Michael Danne, Oliver Mußhoff
}

Status: Published as DARE Discussion Paper No. 1907 (2019).

http://hdl.handle.net/10419/206719

\begin{abstract}
Gender determination in incubated eggs (in ovo) has the potential to substitute the highly discussed practice of culling male layer chicks. The aim of this study is to investigate the effect pictures have on peoples' preferences towards in ovo sexing at different stages of embryonic development as an alternative to chick culling. For this purpose, an online survey was conducted with a representative sample of 482 respondents in Germany. A withinsubject design with two choice experiments was used to investigate the influence pictures have on respondents' preferences and willingness to pay (WTP). The first choice experiment contained plain text only; the second contained also pictures of a chick or the incubated eggs at the corresponding stages of development. Findings reveal that in ovo gender determination at each proposed day of incubation (days 1, 4 and 9) was preferred to chick culling. In ovo screening on days 1 and 4 was significantly preferred to day 9. This preference for early gender determination increased significantly as a consequence to the provision of pictures. Results furthermore reveal that a high error rate of gender determination or the lack of a meaningful utilisation of incubated eggs can decrease approval for in ovo gender determination to an extent, where no positive WTP remains. Findings of this study are useful for stakeholders in poultry production when considering the implementation of in ovo gender determination as a morally admissible substitute to chick culling.
\end{abstract}

Keywords chick; choice experiment; egg; gender determination; in ovo; picture 


\section{Conclusion}

The presented dissertation addresses German citizens' preferences and willingness to pay (WTP) for the alternatives to chick culling which will soon make up the offer on the German market: dual-use poultry an in ovo gender determination. The analyses are carried out by the application of discrete choice experiments (DCE). Four scientific articles are presented. The first two studies (chapters II and III) analyze decision behavior regarding the alternatives in ovo gender determination and dual-use poultry in different husbandry systems. The third and fourth study four (chapters IV and V) focus on preferences for different aspects associated with in ovo gender determination technologies as alternatives to chick culling. The fourth study investigates the influence of pictures on respondents' choice behavior in this context. Understanding societal attitudes towards the alternatives to chick culling is important, because chick culling will be legally prohibited in Germany as soon as in ovo gender determination reaches market maturity (German Federal Ministry of Food and Agriculture, 2017). With regard to the future market development and possible regulation of the practice of chick culling, the aim of this work was to gain profound insights into the expectations of consumers towards this highly discussed topic.

The four presented studies address this objective. For this purpose, two DCEs were designed. The first DCE offered a sequence of choice situations between boxes of eggs with different production characteristics and resembled a future purchase situation, in which chick culling will be phased out and only alternatives are available on the market. The DCE presented an every-day purchase situation with a sequence of choices between boxes of organic, freerange and barn eggs to respondents. The three alternative boxes of eggs were described through varying combinations of attributes concerning the handling of male chicks, the certification of production claims and the price.

The second, unlabeled DCE presented a sequence of choices between the alternatives "chick culling" and "in ovo gender determination" at different stages of embryonic development to respondents. Further attributes considered relevant for the approval of these two alternatives were integrated into the DCE: the usage of by-products (screened out eggs or male chicks), the accuracy of gender determination and the cost increase. As one of the aims of this DCE was the investigation of the influence of pictures, within-subject design presented two identical DCEs to respondents. In the first DCE, the "day of gender determination" was described through plain text, in the second DCE it was additionally described through pictures. 
Both DCEs were integrated into separate questionnaires and primary data was obtained from two anonymous online surveys which were conducted with representative samples of the German population in 2018 and 2019.

The first article analyzes aggregated preferences and WTP for the alternatives to chick culling which will soon make up the offer on the German market: dual-use poultry in different husbandry systems and in ovo gender determination. Labeling is crucial in the context of dual-use poultry; preferences for certifying bodies are thus furthermore determined. For this purpose, data from the first DCE was analyzed through the application of random parameters logit models in preference and WTP space. Results show that the topic of chick culling was well-known among the majority of respondents (65\% stating to know already about the practice). It becomes furthermore evident that in ovo screening and dualuse poultry with males in free-range husbandry are statistically significantly preferred over dual-use poultry with males in barn husbandry. Results therefore provide more detailed information on preferences for dual-use poultry than the existing literature, by differentiating between different husbandry types. It becomes obvious that the husbandry type of cockerels is a very crucial characteristic for the successful marketing of eggs from dual-use poultry. On average, respondents stated the highest WTP for eggs associated with the attribute "in ovo screening", followed by eggs associated with dual-use poultry with cockerels in freerange husbandry. This result implies that the future implementation of in ovo gender determination as industry standard is in line with consumer preferences. In contrast, dualuse poultry with cockerels in barn husbandry obtains the lowest approval and results give evidence that it is questionable whether this system will be able to coexist, after in ovo screening has been implemented as industry standard.

Respondents stated a considerable WTP for labels from some of the proposed certification bodies. Highly approved were labels from the animal protection organization and from the state. The German animal protection organization worked firmly towards the introduction of a national animal welfare label and finally introduced its own label, which can already be found on products in supermarkets. The introduction of a German public label was often announced with high publicity in the past. These may be reasons for the high approval of these two options. These findings are furthermore in line with former studies, which identified public authorities trustworthy institutions in the context of food certification (Janssen et al., 2016; Vanhonacker et al., 2010). On the contrary, participants were not willing to pay more for the labelled products with retailer certification. This result is 
particularly important against the background of the increasing market power of retailers. Retailers have been very active in defining production standards in recent years (Hatanaka et al., 2005). Our results indicate that they should cooperate with well-established third parties or public institutions in the certification of these standards, in order to meet consumer requirements. Overall, relatively high WTP values for some of the certification bodies indicate that demand for verification of production claims exists among consumers, and that it pays therefore out for producers to cooperate with approved certifying bodies when marketing credence goods.

Also the second study analyzed data obtained from the first DCE by investigating the heterogeneity in preferences and WTP for the chick culling alternatives "in ovo screening" and "dual-use poultry" in barn or free-range husbandry. For this objective, a latent class model was employed in order to divide the sample in sub-segments with homogeneous preferences and make the heterogeneity in preferences interpretable. A model with five classes showed the best fit for the data set and was therefore calculated. Individuals' average class assignment probabilities are all very high, which proves that the latent class approach can capture the heterogeneity in consumer preferences in the case of this study very well. Results reveal interesting insights in the distribution of preferences for chick culling alternatives as well as in the distribution of price sensitivity. Observed segments also differ in socioeconomic characteristics. For one segment ( $24 \%$ of the sample), the product price is the most important attribute and WTP for chick culling alternatives is very small. Also former studies identified segments, whose decisions are mainly based on price (Nilsson et al., 2006; Grunert et al., 2018). For two classes (14\% and 27\% of the sample), the preferred chick culling alternative is the prime importance, meaning that they choose the offered eggs only, when accompanied with the respective attribute. Regarding preferences for alternatives to chick culling, the alternative "in ovo screening" renders the highest WTP estimate for $73 \%$ of the sample. No segments states disapproval of in ovo screening, which is contradictory to the results of Gremmen et al. (2018) who observed disapproval among significant shares of the investigated population. Yet one segment, representing $27 \%$ of the sample, is in favor of dual-use poultry with males in free-range husbandry. Usual buyers of organic eggs have a higher probability to be in this segment, which is in line with the findings of Gangnat et al. (2018). None of the five segments is in favor of dual-use poultry with males in barn husbandry. 
Observed preferences give evidence that expectations towards egg production schemes differ among the population, and that an interest in enhanced animal welfare standards does not necessarily preclude the approval of highly efficient production. Preferences for in ovo gender determination were observed among respondents who are in favor of organic eggs, or among respondents who disapprove barn eggs. The results furthermore confirm that the intended regulation in Germany regarding the phasing out of chick culling does, under the assumptions made regarding the increases of production cost, meet the interest of consumers.

The third article investigated the heterogeneity in consumer attitudes towards relevant topics associated with livestock production, and heterogeneity in preferences and WTP associated with different aspects of the in ovo technology. Particularly, heterogeneity in preferences for the day of gender determination, the usage of screened out eggs or male chicks and the accuracy of gender determination are investigated. For this objective, data obtained from the second survey was analyzed by means of a factor analysis and a latent class analysis. A model with four classes fit the data best and was therefore employed. Again, the application of the latent class model is supported by the precise allocation of respondents to classes.

Results give evidence about heterogeneous preferences towards in ovo gender determination and chick culling. One segment (11\% of the sample) indicates disapproval of both chick culling and in ovo gender determination. As a consequence, members of this segment are widely indifferent about the remaining presented aspects of the in ovo technique. This could indicate that respondents of this class would be in favor of other solutions as e.g. dual-use poultry, which were not given as an alternative. The remaining three classes differ in their preferences for the day of gender determination, but are rather homogeneous in preferences for the usage of by-products. A share of $41 \%$ of the sample has a rather critical view of in ovo gender determination and approves only early gender determination, at stages of embryonic development when pain perception is physiologically impossible. $48 \%$ approve all proposed in ovo technologies in comparison to chick culling. The usage of by-products as pet food or fodder was evaluated as superior in comparison to the use of screened out eggs in the chemical industry or no use/waste. The error rate of gender determination has a statistically significantly negative impact on choice probability in all classes. Interestingly, the attributes "usage" and "error rate" proved to be very important for the majority of the sample, which is in line with previous findings (Leenstra et al., 2011). For $20 \%$ of respondents, in ovo screening is not the preferred alternative per se. For this share of the sample, unfortunate characteristics of in ovo technologies can reduce the approval for this 
alternative to a degree that no positive WTP remains. In this case, chick culling could even be the preferred alternative, under certain circumstances.

Heterogeneous price sensitivity is found among segments. WTP for proposed attributes differs therefore. WTP for the attribute "day of gender determination" is highest, but also a meaningful use of by-products and a low error rate some generate considerable WTP. This is interesting, as these characteristics are not associated with animal welfare and do not render an apparent advantage for the product. Overall, the results show that in ovo gender determination as an alternative to chick culling must be thought of holistically. It does not per se represent an improvement for all consumers, just because it ends the culling of chicks.

The fourth study analyzes consumer preferences for in ovo gender determination at different stages of embryonic development as an alternative to chick culling, and investigates whether the provision of pictures of incubated eggs or a chick influences respondents' choice behavior for these alternatives. For this research aim, data from the second survey is investigated by means of random parameters logit models in WTP space. The within-subject design with two identical choice experiments - first only equipped with text and then also with pictures - allows for this analysis.

Firstly, results give evidence that the awareness of the culling of male chicks is with $79 \%$ of participants very high. Secondly, chick culling is stated as worst alternative in both DCEs ceteris paribus. Thirdly, statistically significant differences in the choice behavior between the two DCE rounds exist. Participants are more inclined to choose any of the proposed alternatives in the scenario with text. Statistically significant differences in choice behavior are observed for the levels of the attribute "day of gender determination": gender determination at day 9 of incubation increases choice probability in the without-pictures model, whereas it decreases choice probability in the with-pictures setting. In contrast, choice probability for early gender determination days rises under the with-pictures setting. This can be due to the fact that the moral status given to chicken embryos is considered to rise with increasing embryonic development (Strong, 1997), and this development is well visible on pictures of incubated eggs (at the proposed days 1 and 4 of incubation, not much more than the yolk is visible; at day 9, the shape of the chick is already well recognizable, the eyes are already formed). No statistically significant changes in choice behavior are found for the attribute usage, except a small increase in preference for the attribute level 
"chemical industry". For the attribute "error rate", no statistically significant difference in choice behavior could be found between the without-pictures and with-pictures scenario.

Pictures critically influence the debate about farm animal welfare (Busch \& Spiller, 2018). The advanced embryonic development at day 9 of incubation, giving strong association with a chick, could be an open flank of the respective in ovo gender determination technology, as the images of the embryo might trigger emotional resonance and societal concern. Results of the fourth study indicate again the importance of a meaningful use of by-products and a high accuracy in the gender determination process. The importance of these production attributes should be addressed by producers and marketers. These characteristics should be communicated clearly to consumers, as they seem to be crucial attributes for the acceptance of in ovo gender determination as a morally admissible alternative to chick culling.

The four articles which are presented in this dissertation provide comprehensive, in-depth insights into societal attitudes towards the economical and ethical problems associated with the practice of chick culling and its alternatives. The results should be understood as guidelines in the search and implementation of a publicly accepted and morally preferable substitute to the current practice of chick culling. Findings are particularly valuable for stakeholders in poultry production when evaluating future market developments. Results show that there will probably be no one universally approved solution to the problem of chick culling. Consumers differ in price sensitivity and expectations towards chick culling alternatives. For some individuals, economic aspects are decisive, for others ethical ones. While a low price is the decisive attribute for certain consumer segments, other individuals are willing to pay an undefined high amount for their preferred alternative. While some consumer segments accept only their one preferred alternative, others are willing to make tradeoffs regarding production attributes or price. While some individuals see the alternative of chick culling in less efficient dual-use poultry, others assume the solution in technological advances for highly efficient livestock farming.

At the time of the study, not all alternatives to chick culling which might be relevant in the coming years were available on the market. This made the employment of a stated preference approach necessary. Out of a number of reasons, results obtained from stated preference methods might be exposed to hypothetical bias (Lusk \& Schroeder, 2004; Morrison \& Brown, 2009). Future research should therefore verify the findings from the four presented articles through revealed preferences methods, employing real economic incentives. 
While the future of animal husbandry is currently being passionately discussed by practitioners, animal welfare advocates and politicians, one fact is certain: economic goals and ethical considerations will continuously influence and shape it. Thornton (2010) discusses ethical concern as one crucial future driver of trends in livestock farming in Europe. Due to international trade, the national regulation of livestock production standards might be increasingly subject to difficulties in the future, as it can lead to competitive disadvantages for national producers. An increasing number of changes in livestock farming standards might therefore prospectively be implemented by companies as food corporations. This shift assigns considerable responsibility to the consumer. As a result, public opinion might gain importance compared to scientific evidence, which has in the past been the basis for legal regulation. The agricultural sector should thus actively participate in the formation of societal opinion.

Societal attitudes towards animals have evolved in the past, shape livestock husbandry in the present and will evolve in the future. A productive dialogue between consumers, producers and political decision makers is necessary in order to reconcile the requirements of the various stakeholders. In this way, a sustainable change to more ethical production schemes, which are more accessible for consumers and present marketing possibilities for producers, is possible. 


\section{References}

Busch, G., \& Spiller, A. (2018). Pictures in public communications about livestock farming. Animal Frontiers, 8(1), 27-33.

Gangnat, I. D. M., Mueller, S., Kreuzer, M., Messikommer, R. E., Siegrist, M., \& Visschers, V. H. M. (2018). Swiss consumers' willingness to pay and attitudes regarding dualpurpose poultry and eggs. Poultry Science, 97(3), 1089-1098.

German Federal Ministry of Food and Agriculture. (2017). Alternativen zum Töten männlicher Küken [Alternatives to the culling of male chicks]. Accessed 3 May 2019. https://www.bmel.de/DE/Tier/Tierwohl/_texte/Tierwohl-Forschung-In-Ovo.html

Gremmen, B., Bruijnis, M. R. N., Blok, V., \& Stassen, E. N. (2018). A Public Survey on Handling Male Chicks in the Dutch Egg Sector. Journal of Agricultural and Environmental Ethics, 31(1), 93-107.

Grunert, K. G., Sonntag, W. I., Glanz-Chanos, V., \& Forum, S. (2018). Consumer interest in environmental impact, safety, health and animal welfare aspects of modern pig production: Results of a cross-national choice experiment. Meat Science, 137, 123-129.

Hatanaka, M., Bain, C., \& Busch, L. (2005). Third-party certification in the global agrifood system. Food Policy, 30(3), 354-369.

Janssen, M., Rödiger, M., \& Hamm, U. (2016). Labels for Animal Husbandry Systems Meet Consumer Preferences: Results from a Meta-analysis of Consumer Studies. Journal of Agricultural and Environmental Ethics, 29(6), 1071-1100.

Leenstra, F., Munnichs, G., Beekman, V., van den Heuvel-Vromans, E., Aramyan, L., \& Woelders, H. (2011). Killing day-old chicks? Public opinion regarding potential alternatives. Animal Welfare, 20(1), 37-45.

Lusk, J. L., \& Schroeder, T. C. (2004). Are Choice Experiments Incentive Compatible? A Test with Quality Differentiated Beef Steaks. American Journal of Agricultural Economics, 86(2), 467-482.

Morrison, M., \& Brown, T. C. (2009). Testing the Effectiveness of Certainty Scales, Cheap Talk, and Dissonance-Minimization in Reducing Hypothetical Bias in Contingent Valuation Studies. Environmental and Resource Economics, 44(3), 307-326. 
Nilsson, T., Foster, K., \& Lusk, J. L. (2006). Marketing Opportunities for Certified Pork Chops. Canadian Journal of Agricultural Economics/Revue canadienne d'agroeconomie, 54(4), 567-583.

Strong, C. (1997). The moral status of preembryos, embryos, fetuses, and infants. The Journal of Medicine and Philosophy, 22(5), 457-478.

Thornton, P. K. (2010). Livestock production: Recent trends, future prospects. Philosophical transactions of the Royal Society of London. Series B, Biological sciences, 365(1554), 2853-2867.

Vanhonacker, F., van Poucke, E., Tuyttens, F., \& Verbeke, W. (2010). Citizens' Views on Farm Animal Welfare and Related Information Provision: Exploratory Insights from Flanders, Belgium. Journal of Agricultural and Environmental Ethics, 23(6), 551-569. 


\section{Publication List}

\section{Papers in peer-reviewed scientific journals:}

Reithmayer, C., and Mußhoff, O. (2019): Consumer preferences for alternatives to chick culling in Germany, Poultry Science, DOI: 10.3382/ps/pez272.

Reithmayer, C., Mußhoff, O., and Danne, M. (forthcoming): Alternatives to culling male chicks - the consumer perspective, British Food Journal, DOI: BFJ-05-2019-0356.

\section{Conference contributions:}

Reithmayer, C., and Mußhoff, O. (2019): Consumer preferences for alternatives to chick culling in Germany. Accepted for oral presentation at the 168th EAAE seminar on "Behavioural Perspectives in Agricultural Economics and Management", 6-7 February 2019, in Uppsala, Sweden.

\section{Discussion/working papers}

Reithmayer, C., Danne, M., and Mußhoff, O. (2019): Societal attitudes towards in ovo gender determination as an alternative to chick culling, DARE Discussion Paper 1906, University of Göttingen.

Reithmayer, C., Danne, M., and Mußhoff, O. (2019): Look at that! - The effect pictures have on consumer preferences for in ovo gender determination as an alternative to culling male chicks, DARE Discussion Paper 1906, University of Göttingen. 


\section{Erklärung über den geleisteten Eigenanteil der Arbeit}

Im ersten Beitrag „Alternatives to culling male chicks - the consumer perspective“, der in Zusammenarbeit mit Prof. Dr. Oliver Mußhoff und Dr. Michael Danne verfasst wurde, sind folgende Bereiche von mir übernommen worden: konzeptionelle Entwicklung des Designs in enger Zusammenarbeit mit Dr. Michael Danne und Prof. Dr. Oliver Mußhoff. Entwicklung des Fragebogens, Design des Discrete Choice Experiments, Datenerhebung, konzeptionelle Entwicklung des Beitrages, Berechnungen, Interpretation der Ergebnisse. Das Verfassen des Beitrags wurde unter der Beratung von Prof. Dr. Oliver Mußhoff und Dr. Michael Danne durchgeführt.

Im zweiten Beitrag „Consumer preferences for alternatives to chick culling in Germany“, der in Zusammenarbeit mit Prof. Dr. Oliver Mußhoff verfasst wurde, sind folgende Bereiche von mir übernommen worden: konzeptionelle Entwicklung des Beitrags in enger Zusammenarbeit mit Prof. Dr. Oliver Mußhoff. Design des Discrete Choice Experiments, Datenerhebung, Durchführung der Berechnungen. Interpretation der Ergebnisse und Verfassen des Beitrags in enger Abstimmung mit Prof. Dr. Oliver Mußhoff.

Im dritten Beitrag mit dem Titel ,Societal attitudes towards in ovo gender determination as an alternative to chick culling", der in Zusammenarbeit mit Prof. Dr. Oliver Mußhoff und Dr. Michael Danne verfasst wurde, sind folgende Bereiche von mir übernommen worden: konzeptionelle Entwicklung des Designs und Fragebogens in enger Zusammenarbeit mit Dr. Michael Danne und Prof. Dr. Oliver Mußhoff. Berechnung des Designs des Discrete Choice Experiments, Datenerhebung, konzeptionelle Entwicklung des Beitrages, Berechnungen, Interpretation der Ergebnisse. Das Verfassen des Beitrags wurde unter der Beratung von Dr. Michael Danne und Prof. Dr. Oliver Mußhoff durchgeführt.

Im vierten Beitrag „Look at that! - The effect pictures have on consumer preferences for in ovo gender determination as an alternative to culling male chicks", der in Zusammenarbeit mit Dr. Michael Danne und Prof. Dr. Oliver Mußhoff verfasst wurde, sind folgende Bereiche von mir übernommen worden: konzeptionelle Entwicklung des Designs und Fragebogens in enger Zusammenarbeit mit Dr. Michael Danne und Prof. Dr. Oliver Mußhoff. Berechnung des Designs des Discrete Choice Experiments, Datenerhebung. Die Berechnungen wurden von Dr. Michael Danne ausgeführt. Die Interpretation der Ergebnisse und das Verfassen des Beitrags wurden in enger Abstimmung mit Dr. Michael Danne und unter der Beratung von Prof. Dr. Oliver Mußhoff durchgeführt. 


\section{Eidesstattliche Erklärungen}

Hiermit erkläre ich eidesstaatlich, dass:

1. Diese Arbeit weder in gleicher noch in ähnlicher Form bereits anderen Prüfungsbehörden vorgelegen hat.

2. Ich mich an keiner anderen Hochschule um einen Doktorgrad beworben habe.

Göttingen, den 12. Dezember 2019

(Unterschrift)

Hiermit erkläre ich eidesstaatlich, dass diese Dissertation selbstständig und ohne unerlaubte Hilfe angefertigt wurde.

Göttingen, den 12. Dezember 2019

(Unterschrift) 